Revista Brasileira de Informática na Educação - RBIE Brazilian Journal of Computers in Education (ISSN online: 2317-6121; print: 1414-5685)

http://br-ie.org/pub/index.php/rbie

\begin{tabular}{llll}
\hline Submission: $29 / 10 / 2020 ;$ & $1^{\text {st }}$ round notif.: $18 / 12 / 2020 ;$ & New version: $18 / 01 / 2021 ;$ & $2^{\text {nd }}$ round notif.: 02/02/2021; \\
Camera ready: $16 / 02 / 2021 ;$ & Edition review: $19 / 02 / 2021 ;$ & Available online: $12 / 03 / 2021 ;$ & Published: $12 / 03 / 2021 ;$
\end{tabular}

\title{
A Licenciatura em Computação no Brasil: histórica e contexto atual
}

Title: The Degree in Computing in Brazil: historical and current context

\author{
Ana Cristina Oliveira Linhares \\ IFBA - Campus Eunápolis \\ anacrislinhares@hotmail.com
}

\author{
Kátia Silva Santos \\ IFBA - Campus Porto Seguro \\ katiameireles70@gmail.com
}

\begin{abstract}
Resumo
As transformações sociais nos obriga a (re)pensar a educação, a ressignificar as práticas pedagógicas criando situações de aprendizagens condizentes com as necessidades do mundo atual. A educação, hoje, vem cada vez mais utilizando artifícios tecnológicos como meio para aprimorar o processo de ensino aprendizagem, e para acompanhar tal feito, as escolas necessitam de aparato não só material como humano. O professor nesse contexto é convocado a mudar suas práticas, a aderir a uma era que exige competências voltadas para uso das tecnologias digitais. Assim, a educação Brasileira por meio de Políticas públicas, trava uma luta de décadas para informatizar as escolas e por consequência, inserir profissional licenciado em Computação no contexto educacional. Pois, o ensino da computação e da informática tem sido atribuída a este profissional. A Licenciatura em Computação objetiva formar cidadãos para o exercício tanto em corporações nas áreas voltadas para a computação quanto a prática pedagógica em ambientes educacionais. Neste sentido, este artigo tem como objetivo remontar a trajetória de implementação dos Cursos de Licenciatura em Computação, no Brasil. A abordagem proposta foi qualitativa, por meio de uma pesquisa histórica. Inicia-se o texto inferindo sobre a notoriedade e importância destes cursos para o nosso tempo; segundo sobre a necessidade da formação deste futuro docente ser aprimorada na prática por meio de implementações de metodologias inovadoras, vinculadas tais como a prática de resolver problemas no cotidiano das escolas; e terceiro a necessidade de ampliação do campo de emprego para estes docentes no contexto das Redes de ensino.
\end{abstract}

Palavras-Chave: Licenciatura em Computação; Diretrizes Curriculares; Informática; Ensino.

\begin{abstract}
Social transformations oblige us to (re) think about education, to reframe pedagogical practices, creating learning situations consistent with the needs of today's world. Today, education is increasingly using technological devices as a means to improve the teaching-learning process, and to accompany this achievement, schools need not only material but also human apparatus. The teacher in this context is called upon to change his practices, to adhere to an era that requires competencies focused on the use of digital technologies. Thus, Brazilian education through public policies, wages a decades-long struggle to computerize schools and, consequently, to insert a professional with a degree in Computing in the educational context. For, the teaching of computing and informatics has been attributed to this professional. The Degree in Computing aims to train citizens to exercise both in corporations in the areas focused on computing and the pedagogical practice in educational environments. In this sense, this article aims to trace the implementation trajectory of the Computer Science Degree Courses in Brazil. The proposed approach was qualitative, through historical research. The text begins by inferring about the notoriety and importance of these courses for our time; second on the need for the training of this future teacher to be improved in practice through the implementation of innovative, linked methodologies such as the practice of solving problems in the daily life of schools; and third, the need to expand the field of employment for these teachers in the context of education networks. Keywords: Degree in Computing; Curricular Guidelines; Informatics; Teaching.
\end{abstract}

Cite as: Linhares, A.C.O., \& Santos, K. S. (2021). The Degree in Computing in Brazil: historical and current context (A Licenciatura em Computação no Brasil: histórica e contexto atual). Brazilian Journal of Computers in Education (Revista Brasileira de Informática na Educação - RBIE), 29, 188-208. DOI: 10.5753/RBIE.2021.29.0.188 


\section{Introdução}

Em um cenário caracterizado pelo avanço e crescimento das tecnologias da informação e da comunicação, tanto o tablet, quanto o uso do celular, bem como do computador tornaram-se ferramentas que auxiliam no aprendizado. A computação está integrada em diversas áreas e atividades tanto profissional quanto social. Assim, não podemos ignorar a urgente necessidade da inserção desta na educação como um todo. Deixando claro que a Computação como ciência vai além do uso de artefatos tecnológicos. Apesar desta inclusão da computação não ser obrigatória nos currículos escolares, entende-se que é apenas uma questão de tempo para que esse complemento venha tornar-se um apoio indispensável aos estudos dos discentes e docentes. Pois,

Com esse novo suporte de informação e de comunicação emergem gêneros de conhecimento inusitados, critérios de avaliação inéditos para orientar o saber, novos atores na produção e tratamento dos conhecimentos. Qualquer política de educação terá que levar isso em conta. (Lévy, 1999, p. 168).

Neste contexto, as Licenciaturas em Computação ganham destaque, tornando-se mola propulsora para a mudança que se opera na prática do currículo, das escolas e da sala de aula. Ao licenciado em computação são planejadas e conferidas competências capazes de implementar no currículo e reconhecer a importância do pensamento computacional ${ }^{1}$ no dia a dia como sua aplicação em várias situações. Importante destacar que:

A licenciatura é uma licença, ou seja, trata-se de uma autorização, permissão ou concessão dada por uma autoridade pública competente para o exercício de uma atividade profissional, em conformidade com a legislação. A rigor, no âmbito do ensino público, esta licença só se completa após o resultado bem sucedido do estágio probatório exigido por lei. (Parecer CNE/CP nº 28/2001).

Ao futuro docente em Computação cabe o exercício da docência em computação. Alinhado às exigências da lei no Parecer CNE/CP n ${ }^{0}$ 28/2001 e ao contexto de uma sociedade sedenta por tecnologia, o curso de Licenciatura em computação atende uma demanda das escolas correlacionando teoria e prática, aliando educação e computação, favorecendo a aquisição de múltiplos conhecimentos. Conhecimento este que vai além de ensinar a utilização das tecnologias. Tais aptidões conferem a este profissional também estimular nos estudantes o desenvolvimento do pensamento computacional, assim como a autonomia para resolver problemas voltados à ciência da computação e do dia a dia, além de um trabalho interdisciplinar. "A formação interdisciplinar do licenciado em computação é fundamental para garantir a qualidade desses recursos e sua integração aos processos pedagógicos e espaços escolares." (Raabe, Nunes \& Falcão, 2018, p.36).

A interdisciplinaridade é uma característica da Licenciatura em computação, atendendo assim, a LEI No 9.394, de 20 de dezembro de 1996, Lei de Diretrizes e Bases da Educação Nacional:

no Art. $1^{\circ}$, parágrafo $\S 2^{\circ}$, "A educação escolar deverá vincular-se ao mundo do trabalho e à prática social". Vivendo em sociedade cada vez mais digitalizada, para acompanhar essa tendência e adequar o educando

\footnotetext{
${ }^{1}$ Pensamento Computacional: envolve as capacidades de compreender, analisar, definir, modelar, resolver, comparar e automatizar problemas e suas soluções, de forma metódica e sistemática, por meio do desenvolvimento de algoritmos; (Base Nacional Comum Curricular - BNCC, 2017, p. 474).
} 
ao mundo do trabalho à prática social é necessário que medidas sejam adotadas.

É necessário reconhecer que estamos vivendo uma nova era, a chamada era digital, a qual parece exigir conhecimento, habilidades e atitudes do aluno e do professor frente ao século XXI, onde, novas demandas exige nova estruturação pedagógica “(...) que corresponde às demandas do estudante desta época, preparando-o para o futuro" (Base Nacional Comum Curricular - BNCC, 2017, p.05). Conforme descrita na BNCC (2017), $5^{\circ}$ competência geral,

Compreender, utilizar e criar tecnologias digitais de informação e comunicação de forma crítica, significativa, reflexiva e ética nas diversas práticas sociais (incluindo as escolares) para se comunicar, acessar e disseminar informações, produzir conhecimentos, resolver problemas e exercer protagonismo e autoria na vida pessoal e coletiva. (p.09).

Neste contexto, é necessário estar atento, pois a tecnologia da informação e comunicação deve ser utilizada como meio, como apoio para o desenvolvimento da aprendizagem e assim explicitar o que diz a $1^{\mathrm{a}}$ competência geral na BNCC (2017),

Valorizar e utilizar os conhecimentos historicamente construídos sobre o mundo físico, social, cultural e digital para entender e explicar a realidade, continuar aprendendo e colaborar para a construção de uma sociedade justa, democrática e inclusiva. ( p.09)..

A computação, como uma ciência é, portanto, inseparável de seu contexto histórico e social, devendo contribuir/promover a inclusão no que se refere ao bom uso, à compreensão e mesmo a produção dos recursos tecnológicos a ela vinculados (Currículo de Referência para cursos de Licenciatura em Computação - (CR-LC/2002), 2002).

Neste sentido, este artigo tem como objetivo remontar a trajetória de implementação dos Cursos de Licenciatura em Computação, no país. Tal estudo destina-se aos estudantes, interessados e aos egressos do mesmo. A abordagem qualitativa, por meio de uma pesquisa histórica, na qual foram levantados fatos, decretos, ações governamentais e artigos, os quais permitiram erigir esta trajetória e fundamentam o texto.

O artigo está organizado da seguinte forma: primeiro, revisão de literatura sobre o trabalho é apresentada; em um segundo momento, descrevemos um breve resumo sobre a computação no Brasil; na seção seguinte, são anunciadas o curso de Licenciatura em Computação e suas abrangências. Por fim, apresentamos as considerações finais.

\section{A abordagem metodológica: perspectiva histórica}

Ao assumir a perspectiva histórica, afirma-se que é a partir da História que os acontecimentos e as estruturas de uma sociedade podem ser analisados (Fontoura, Alfaia \& Fernandes, 2013). Bachelard (1977) e epistemologia Histórica sugere pensar a ciência e produzir conhecimento, como uma forma de pesquisa cuja base se encontra na defesa de que a história é central para uma melhor compreensão e reflexão da humanidade. Tal formato metodológico impulsiona e ajuda a construir um olhar interdisciplinar, ressaltando a importância do diálogo, sendo possível que esta seja realizada paralelamente com outras abordagens metodológicas de pesquisa, tais como, análise de conteúdo, análise de discurso, estatística, dentre outros.

Segundo Appio et. e tal (2017), o destaque da pesquisa histórica é a coleta de informações e da interpretação ou da análise de dados, objetivando para desvendar o desconhecido, para 
responder a perguntas, para procurar implicações ou relações de acontecimentos e realizações do passado das pessoas, organismos ou instituições.

No Brasil, dentre os interesses da aplicação da perspectiva histórica. Nesse texto, a perspectiva histórica contribuirá para a construção de uma olhar reflexivo sobre a retomada da trajetória histórica do processo de implantação dos cursos de Licenciatura em Computação no País.

Este texto, remonta a trajetória de implementação dos Cursos de Licenciatura em Computação, no país, por meio da busca de fatos históricos vinculados desde as primeiras iniciativas de implantação destes cursos até os dias atuais. Neste sentido, o tipo de pesquisa escolhida colabora e caracteriza o estudo

\section{Revisão de Literatura}

As tecnologias têm trazido experiência marcante para a sociedade. O que implica diretamente no meio educacional. Trazendo saberes que se somam. Saberes de natureza tecnológica somam-se aos conhecimentos tradicionalmente considerados necessários para o sujeito enquanto ser social e produtivo, a inserção da computação. Matos (2013, p. 27). A inserção da computação na educação pode formar indivíduos com conhecimentos que vão além da compreensão de máquinas. Essa roupagem fez emergir um novo perfil profissional, o professor de Computação formado no curso de Licenciatura em Computação.

Segundo as Diretrizes Curriculares Nacionais para cursos de Computação, a atuação destes não será apenas para o ensino de informática, mas para o desenvolvimento de habilidades e competências junto aos alunos com a realização de atividades didático-pedagógica com auxílio das Tecnologias da Informação e Comunicação (TIC), desenvolvendo assim nos alunos o uso crítico-reflexivo do computador. Autores como Castro e Vilarim (2013), Matos (2013), Luciano e Santos (2013), Santos, Silva e Hinterholz (2017b), Priecht e Pazeto (2010), dentre outros, discutem alguns passos que foram dados para a implementação da informática na educação e significativamente no Brasil. Também elencam algumas preocupações e ressalvas que podem ser consideradas para uma melhoria do curso.

Matos (2013) traz uma reflexão sobre a identidade profissional do Licenciado em Computação, e no que tange a sua formação numa interdisciplinaridade indissociável e bem estruturada. De acordo com ele, a identidade docente tem sido estudada por várias outras áreas, mas existe uma preocupação com a identidade docente do Licenciado em Computação quanto “(...) a necessidade de definição e reconhecimento de uma identidade profissional própria do licenciado enquanto educador, diferenciado do bacharel". O que também demonstra Castro e Vilarim (2013) na busca pela consolidação e valorização do curso. Para complementar esse fortalecimento identitário, o Currículo de Referência para cursos de Licenciatura em Computação (CR-LC) da Sociedade Brasileira de Computação (SBC, 2017) traz documentos que fortemente comprovam e justificam o curso Licenciatura em Computação.

Outro fator que eles (Matos, 2013; Castro \& Vilarim 2013) chamam a atenção, em questão do pouco reconhecimento do curso e o fato do ensino básico não ter inserido em seus currículos disciplinas específicas para a atuação do egresso de Licenciatura em computação o que é corroborado por Santos, Silva e Hinterholz (2017b) quando diz que a carreira do Licenciado em Computação ainda não está plenamente construída. Isto se deve aos poucos espaços legalmente constituídos para o profissional no contexto da Educação Básica. Mas, como afirma Castro e Vilarim (2013), o licenciado em Computação não deve se limitar apenas ao espaço escolar, 
(...) pois seu agir educacional pode e deve estar presente na construção de softwares educativos e objetos de aprendizagem, na atuação em equipes multidisciplinares, em ambientes de educação formal e não-formal. Ou seja, a principal crítica, na realidade - a da ausência de espaço de atuação - revela-se como oportunidade de novos espaços, sem perder sua essência educacional e elevando a níveis mais amplos seu exercício. (p. 21).

Apesar desse vasto campo de atuação, Santos, Hinterholz e Silva (2017a) ainda consideram questões desafiadoras, pois são poucos os espaços legalmente constituídos nas empresas e como professor de Computação na Educação Básica.

Em um mapeamento dos cursos de Licenciatura em Computação no Brasil, Prietch e Pazeto (2010) sugerem uma matriz curricular com habilidades adequadas para egressos se apropriarem do mercado de trabalho. Castro e Vilarim, (2013), consideram que: "Formar um profissional de Computação implica em proporcionar uma consistente base teórica e uma fluente prática profissional que o permita transitar nos desafios do novo, o que não é algo trivial". Pois, na formação desses profissionais somam-se habilidades técnicas e pedagógicas com forte ênfase em Ciência da Computação. Almejando um perfil profissional com saberes científicos, pedagógicos e tecnológicos.

Conforme de Almeida e Mateus (2015): a interdisciplinaridade também se inclui como habilidade do licenciado, por permitir a inclusão da informática no processo de ensino e aprendizagem dos conteúdos ministrados por outras áreas do conhecimento por meio da interação com professores dos diferentes níveis e modalidades de ensino. Corroborado por Matos (2013) quando diz que a formação do Licenciado em Computação é indissociável da interdisciplinaridade. Os licenciados além de atuarem como professores, podem também tecer parcerias com professores de outras disciplinas, pois possuem "potencial didático" e conhecimentos tecnológicos que podem auxiliar em projetos com uso tecnológico e assim promover o enriquecimento das atividades docentes. (de Almeida \& Mateus, 2015). Nesse seguimento Castro e Vilarim (2013) acrescenta uma provável atuação destes “(...) em equipes multidisciplinares, na transposição pedagógica de conteúdos disciplinares para tecnologias e metodologias educacionais". Que deve atuar como agente integrador no processo de ensinoaprendizagem aliando didática e pedagogia aplicando seus conhecimentos de forma criativa e inovadora.

Neste contexto, as DCNs dos cursos de graduação em Computação Brasil (2016) instituem as habilidades e competências esperadas da formação do licenciado em computação, que são:

I - especificar os requisitos pedagógicos na interação humanocomputador;

II - especificar e avaliar softwares e equipamentos para aplicação educacionais e de Educação à Distância;

III - projetar e desenvolver softwares e hardware educacionais e de Educação à Distância em equipes interdisciplinares;

IV - atuar junto ao corpo docente das Escolas nos níveis da Educação

Básica e Técnico e suas modalidades e demais organizações no uso efetivo e adequado das tecnologias da educação;

$\mathrm{V}$ - produzir materiais didáticos com a utilização de recursos computacionais, propiciando inovações nos produtos, processos e metodologias de ensino aprendizagem;

VI - administrar laboratórios de informática para fins educacionais;

VII - atuar como agentes integradores promovendo a acessibilidade digital;

VIII - atuar como docente com a visão de avaliação crítica e reflexiva; IX - propor, coordenar e avaliar, projetos de ensino-aprendizagem assistidos por computador que propiciem a pesquisa. 
Assim, conforme Falcão et al. (2018),

(...) os egressos do curso de LC serão dotados de um repertório de informações e habilidades composto pela pluralidade de conhecimentos teóricos e práticos das áreas de Educação e Computação, o que lhes permitirá atuar profissionalmente em instituições de educação (incluindo as séries finais do Ensino Fundamental, Ensino Médio, Educação Profissional Técnica de nível Médio, demais cursos técnicos e Organizações Não Governamentais), mas também em empresas de consultoria, assessoria e desenvolvimento de tecnologias educacionais.

A partir desses fatores é possível compreender o papel do Licenciado em Computação enquanto profissional integrador pedagógico-tecnológico numa era onde a tecnologia está fortemente presente na sociedade. Fomentando a inclusão digital por meio da educação numa sociedade tecnologicamente atuante em atividades pessoais, sociais e profissionais.

\subsection{As Licenciaturas em Computação no Brasil: segundo uma abordagem histórica}

Nas últimas décadas tem se debatido muito sobre o tema informática e Educação, sobre a inserção das novas tecnologias da informação e comunicação em sala de aula, sobre uma construção de aulas mais significativas, mais interativas com o auxílio das tecnologias. Desde o ano de 1971 que o tema vem sendo discutido no Brasil com o primeiro debate do uso dos computadores na educação. No ano de 1973 aconteceu a inclusão da informática na educação para alunos de Química nos testes com simulações e mais outras experiências no aprimoramento para um ensinoaprendizagem que durou até o ano de 1980. Década que envolveu visitas de cientistas como Seymour Papert e Marvin Minsky, experiências baseadas na teoria de Jean Piaget e nos estudos de Seymour Papert, até a visita de pesquisadores da Unicamp ao MEDIA-Lab do MIT/EUA. No mesmo período em que através da Linguagem de programação Logo se originaram as primeiras investigações sobre o uso dos computadores na educação. Para viabilização destas inovações, uma equipe foi formada e participantes eram composto por representantes da - Secretaria Especial de Informática - SEI, do Ministério da Educação e Cultura - MEC, do Conselho Nacional de Desenvolvimento Científico e Tecnológico - CNPq e da Financiadora de Estudos e Projetos Finep com a necessidade de discutir táticas de planejamento criando assim o I Seminário Nacional de Informática na Universidade de Brasília - UnB. Em 1981 um documento que fundamentou a informática na educação foi elaborado pelo mesmo grupo (Subsídios para a Implantação do Programa Nacional de Informática na Educação), este, recomendando a centralização das iniciativas nacionais nas universidades e não nas secretarias devido à necessidade do conhecimento técnico-científico, dentre outras recomendações. No ano de 1982 o MEC assumiu o compromisso de criar instrumentos e meios para o desenvolvimento acerca das primeiras investigações na área. O II Seminário Nacional de Informática na Educação aconteceu neste mesmo ano na Universidade Federal da Bahia - UFBA, com o envolvimento apenas do MEC, da SEI e do CNPq, trazendo recomendações sobre a inserção de um trabalho interdisciplinar e de outras modalidades de ensino no programa além do $2^{\circ}$ grau.

Já em 1983, o Núcleo Interdisciplinar de Informática Aplicada à Educação - Nied da Universidade de Campinas - Unicamp foi instituído com o apoio do MEC para desenvolvimento do projeto Logo, criado também o projeto Educom, com o objetivo de desenvolver a pesquisa do uso da informática na educação e também voltada à criação de centros-pilotos para o desenvolvimento das pesquisas. Os primeiros convênios entre a Funtevê/MEC com as universidades (UFRGS - Universidades Federais do Rio Grande do Sul, UFPE - Universidade Federal de Pernambuco, UFMG - Universidade Federal de Minas Gerais, UFRJ - Universidade Federal do Rio de Janeiro e Unicamp - Universidade de Campinas) foram firmados em 1984 para início das atividades centros-piloto. Num período de cinco anos o Educom teve uma vasta produção com contribuições significativas para a área da computação e também da educação. 
Presidido pelo secretário-geral do MEC, foi criado o Comitê Assessor de Informática na Educação da Secretaria de Ensino de $1^{\circ}$ e $2^{\circ}$ Graus Caie/Seps, no ano de 1986, dando início a uma nova fase. Tendo em sua formação, profissionais técnico-científicos de relevante competência e de diferentes segmentos da sociedade. No mesmo ano o comitê recomendou a criação do Programa de Ação Imediata em Informática na Educação de $1^{\circ}$ e $2^{\circ}$ Graus, uma ação junto às secretarias estaduais onde o objetivo era a capacitação de professores, o incentivo a produção de software educativo, assim como integralizar as pesquisas que vinham sendo desenvolvidas nas universidades brasileiras. Ainda nesse ano, uma avaliação foi realizada nos centros-piloto, o que, apesar da falta de apoio financeiro por parte de alguns apoiadores (CNPq, Finep e SEI), a avaliação demonstrou que as atividades continuavam a serem desenvolvidas conforme proposto.

Em novembro de 1987 foi realizada a Jornada de Trabalho de Informática na Educação, em Florianópolis. Ano em que também foi criado o Projeto Formar, que objetivava a capacitação de professores para atuação no sistema de ensino estadual público. Entre 1988 e 1989 foi implantado um total de 17 Centros de Informática da Educação - Cieds em diferentes estados. Cada centro era responsável por coordenar e implantar outras unidades, além de cuidar de outros recursos, também se tornaram espaços de aprendizagem informatizados formados por professores de diferentes áreas, além de técnicos e especialistas que atendiam a professores e alunos e também a educação especial. Com uma nova estratégia política do MEC, os Cieds passaram a ser de responsabilidade de cada estado, cabendo a este apenas a formação do professor, os equipamentos e recursos para início das atividades e ao estado, o interesse em dar continuidade ao projeto com recursos próprios.

O Projeto de Informática Educativa na Área de Educação Básica - Coeeba - foi um projeto de cooperação multinacional que envolveu outros países. Depois de tantas investidas o Brasil criou o Programa Nacional de Informática Educativa - Proninfe, que tinha o intuito de desenvolver a informática por meio de uma pedagogia concisa e atualizada a fim de garantir sucesso ao investimento. Estes estavam amparados na constituição das áreas da educação, ciência e tecnologia e seu desenvolvimento e uso da informática abrangiam o ensino de $1^{\circ}, 2^{\circ}$ e $3^{\circ}$ grau e a Educação Especial. Ficando sua coordenação submissa à Secretaria-Geral do MEC. Já em 1997 foi criado o Programa de Informática na Educação - Proinfo com a intenção de inserir a tecnologia na rede pública de ensino para o ensino fundamental e médio. O Projeto Um Computador por Aluno - UCA foi uma iniciativa do Governo Federal com o objetivo de melhorar a qualidade do ensino, distribuindo laptop a cada aluno do ensino básico brasileiro.

Foram vários os caminhos percorridos para a inserção da informática no Brasil e consequentemente na Educação. Ainda na década de 1990, aconteceu a edição do currículo de referência para cursos de graduação em Computação criados pela $\mathrm{SBC}^{2}$, influenciando na formação superior em computação. Período em que também foi constituída a Comissão de Especialistas de Ensino de Computação e Informática do MEC. Este recomendou os padrões de qualidade para os cursos de graduação da área e devido à diversidade de nomenclaturas, os cursos foram padronizados por nomes e perfis: Ciência da Computação, Engenharia de Computação, Licenciatura em Computação e Sistemas de Informação. Apesar das muitas divergências de nomes quanto aos perfis, optou-se pela Licenciatura em Computação. De acordo com Castro e Vilarim (2013, p. 04) as divergências ainda ocorrem com uso de Licenciatura em Computação ou Licenciatura em Informática. Já em 1999 foi proposta a elaboração das diretrizes curriculares. No

\footnotetext{
${ }^{2}$ SBC (Sociedade Brasileira de Computação) - Desempenha um importante papel no ensino da Computação no Brasil. Sua comissão é responsável pela elaboração de Currículos de Referência, pela forma de avaliação dos cursos da área, elaboração dos Referenciais de Formação em Computação (RF) e documentos que deu origem às DCNs. Nos eventos organizados pela SBC acontecem as discussões sobre o ensino de computação de nível superior. Informações que podem ser conferidas em: www.sbc.org.br.
} 
ano de 2002, foi criado Currículo de Referência dos Cursos de Licenciatura em Computação CR-LC/2002 (este tem papel importante na criação do projeto pedagógico) e integralizado as Diretrizes Curriculares Nacionais - DCNs dos Cursos de Graduação na área de Computação.

O Programa Banda Larga nas Escolas - PBLE foi lançado em 2008 pelo governo federal em um acordo do Fundo Nacional de Desenvolvimento da Educação - FNDE com a Agência Nacional de Telecomunicações - ANATEL, em parceria com as Secretarias de Educação estaduais e municipais. A mais recente ação do Proinfo foi a distribuição de tablets para utilização escolar, com a finalidade de uso didático-pedagógico das Tecnologias da Informação e Comunicação TIC e com a oferta de conteúdos e recursos multimídia e digitais.

O curso da Licenciatura em Computação começou a ganhar notoriedade, em 2011 começaram as provas do ENADE, sendo esta específica para o curso. A aprovação das DCNs, pelo Conselho Nacional de Educação aconteceu em 2012, sob o Parecer CNE/CES No 136/2012 e homologada em 2016, definida na Resolução CNE/CES No 5/2016 (MEC, 2016). Esta institui as DCN's para os cursos de graduação na área da Computação que também abrange o Curso de Licenciatura em Computação. Já em 2017, a Sociedade Brasileira de Computação - SBC lança os Referenciais de Formação para os Cursos de Graduação em Computação - RF, elaborado com as características de cada curso. Este em harmonia com as DCNs, servem como referência na organização dos currículos, do projeto pedagógico dos cursos da área de computação, assim "como auxiliar estudantes e interessados nos cursos de Ciência da Computação a compreender a natureza da formação nesta área.” (Parecer SBC-INEP - Reclassificação de cursos, 2018, p. 03).

Segundo os Referenciais de Formação para os Cursos de Graduação em Computação (2017, p. 83), "Cada região exige um perfil de curso diferente, de acordo com a cultura tecnológica presente (ou ausente) na localidade". Cabendo assim, cada instituição adequar os conteúdos às características locais, desde que garantam aos egressos as competências previstas. No Brasil o pioneiro a implantar o curso foi à universidade de Brasília no ano de 1997, iniciando

(...) um curso específico de licenciatura, com foco na Educação Básica e com perspectiva de romper com modelos de formação "3 + 1" calcados na racionalidade técnica, pelos quais se acreditava ser possível formar um professor para a Educação Básica por meio de complementação pedagógica (geralmente de um ano) ao final do bacharelado. (REFERENCIAIS DE FORMAÇÃO PARA OS CURSOS DE GRADUAÇÃO EM COMPUTAÇÃO 2017, p. 83).

Em 1999, abriram-se dois cursos no Nordeste, um no Sul e outro no Sudeste. "Em 2007, na região Centro-Oeste, foram criados 12 novos cursos; na Região Nordeste, 09; na Região Norte, 04; na Região Sul, 11; na Região Sudeste, 22“. (Prietch \& Pazeto, 2010, p. 02), chegando a 58 o número de instituições que ofertaram o curso neste ano. Conforme mostra a figura 01, em 2010, o número de cursos criados superou todos os anos anteriores. Em 2013 já eram "(...) 68 Instituições oferecendo 110 cursos” e “(...) mais de 150 cursos no Brasil no ano de 2017”. (Santos, Silva \& Hinterholz, 2017b, p.02]. 


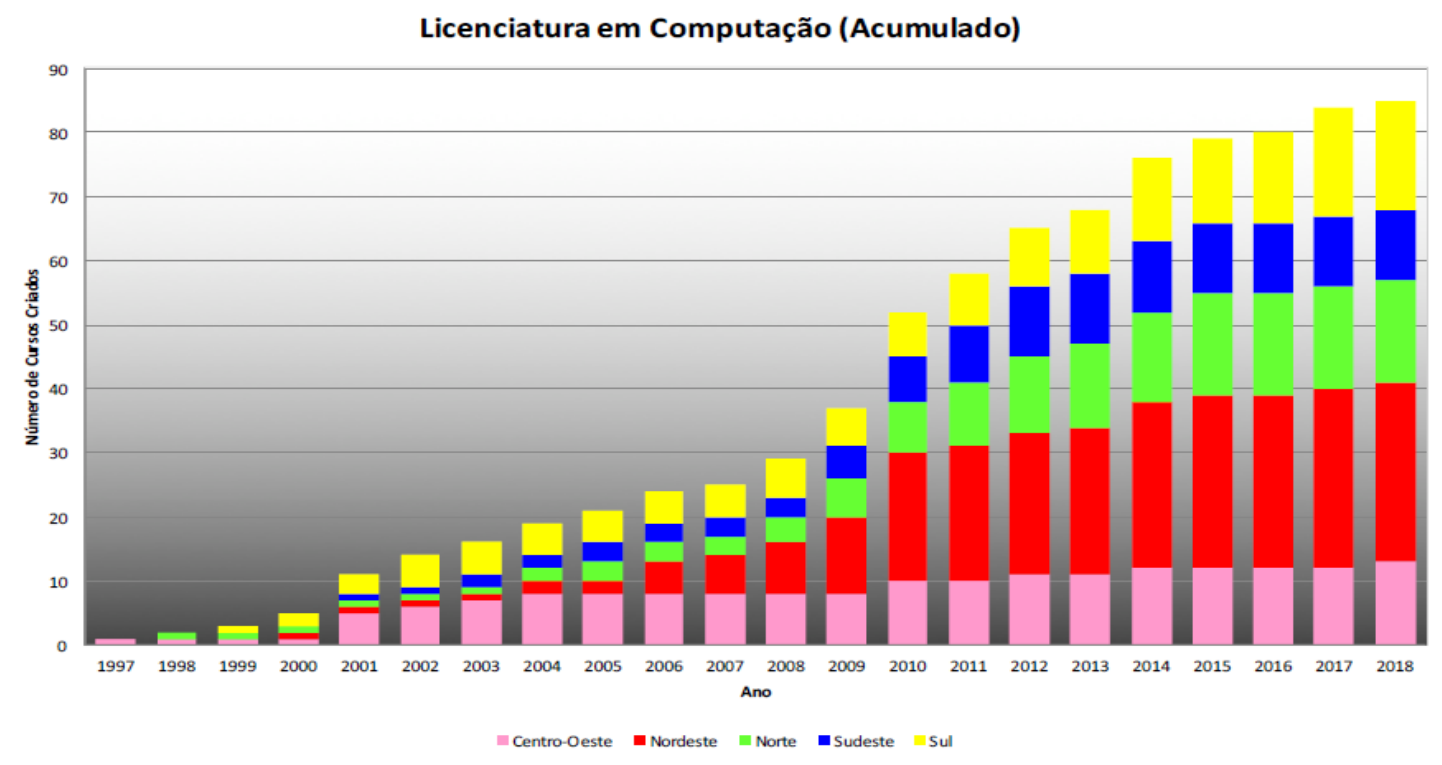

Figura 1: Evolução do curso de Licenciatura em computação no Brasil. Fonte: SBC - Educação Superior em Computação - Estatísticas - 2018.

Estatísticas dos cursos de graduação em Computação da SBC (2018) chama a atenção para a comparação de estatísticas de anos anteriores, pois, entre um ano e outro, alguns "cursos são criados e outros extintos". Em comparação a 2017 para 2018, houve um crescimento de 14,6\% na criação de cursos, além do significativo aumento dos cursos EAD (figura 02). Atentando-se que para a criação de um ambiente AVA, uma plataforma e-learning são “(...) exigidos novos profissionais para o planejamento, criação, desenvolvimento e avaliação desses ambientes e cursos".

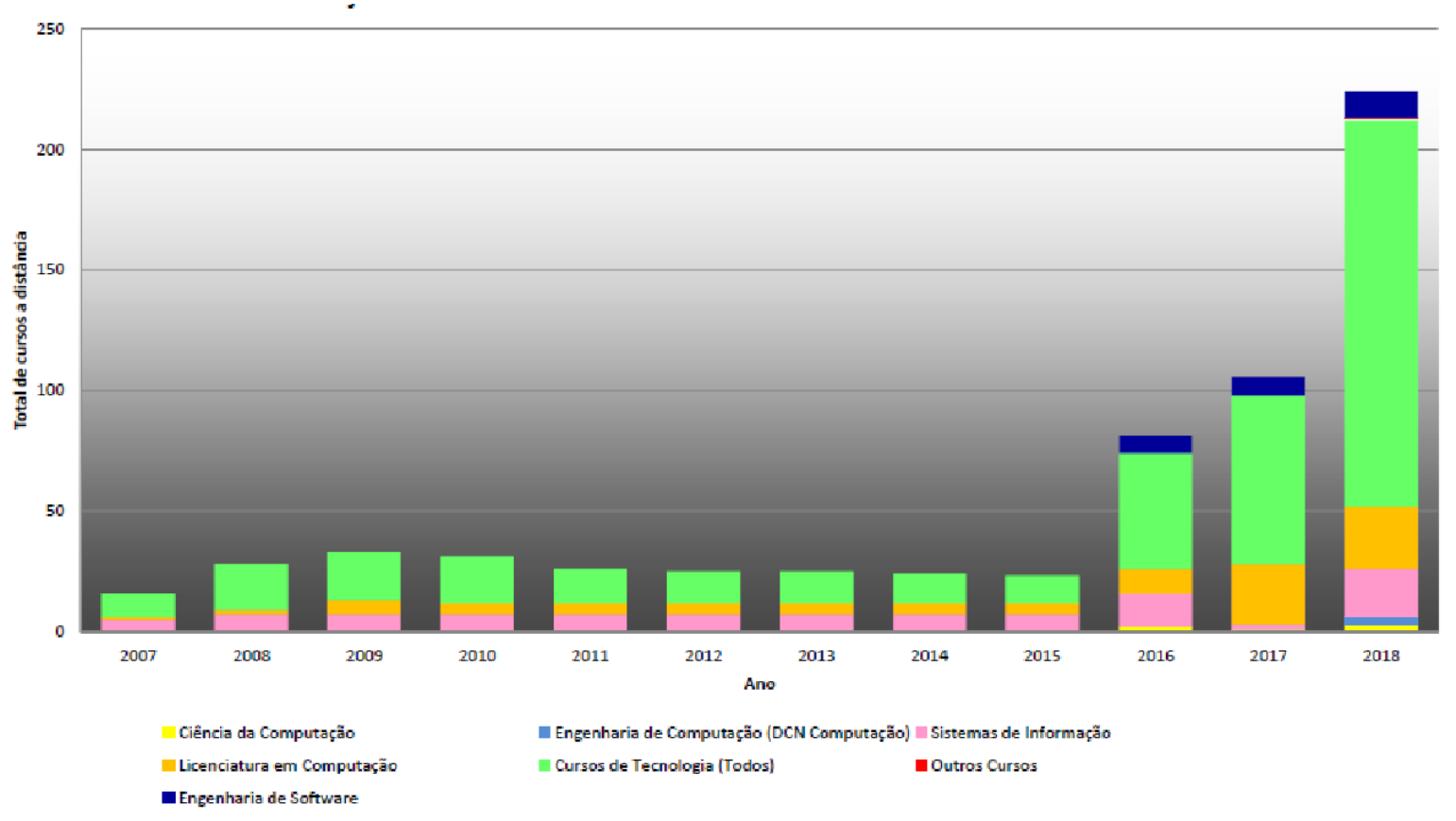

Figura 2: Evolução do Total de curso a Distância entre 2007 e 2018 no Brasil. Fonte: SBC - Educação Superior em Computação - Estatísticas - 2018.

A região Nordeste é uma das regiões onde mais cresce o número de criação de cursos (figura 03). 


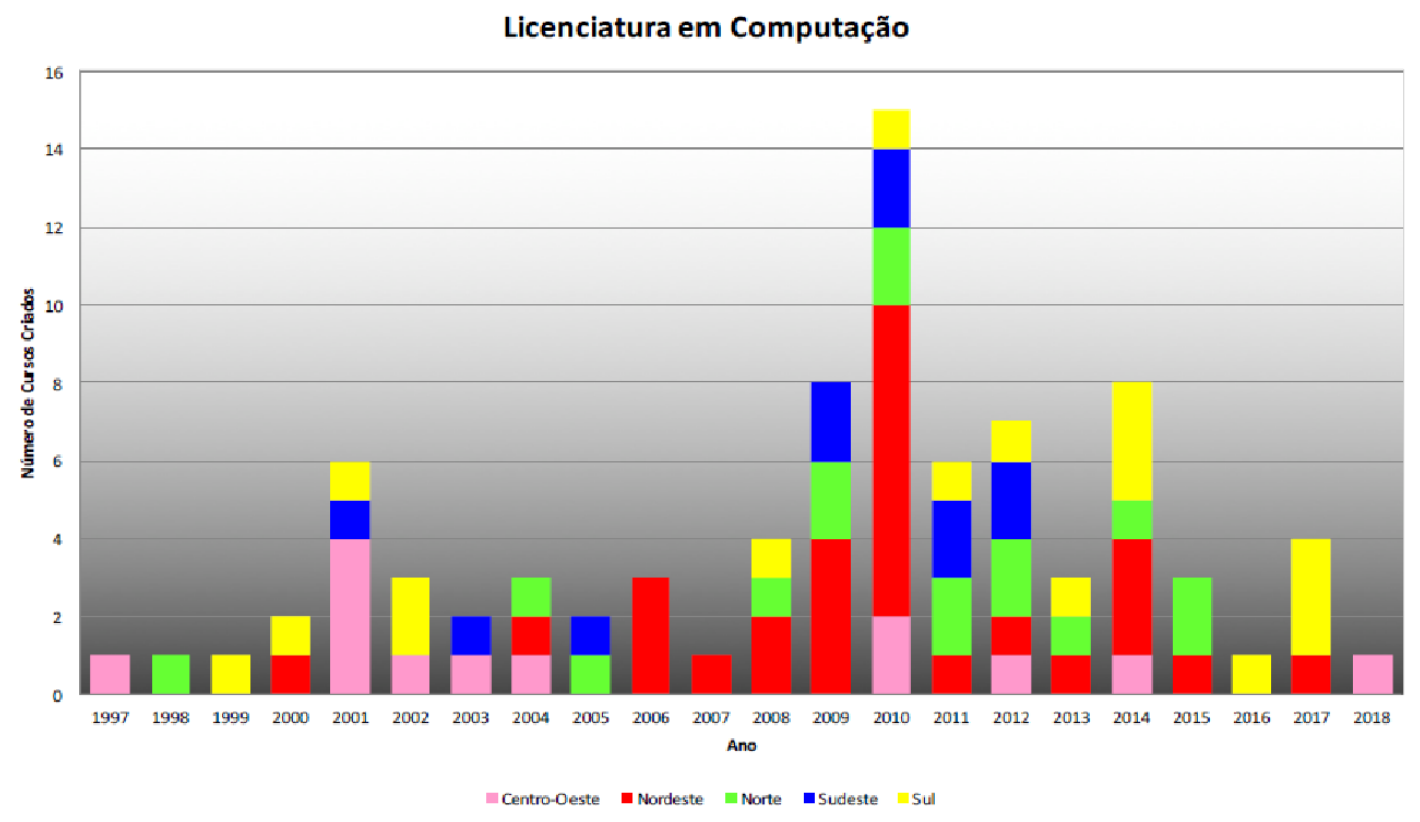

Figura 3: Evolução do curso de Licenciatura em computação por região no Brasil (cursos criados). Fonte: SBC - Educação Superior em Computação - Estatísticas - 2018.

Mesmo com o crescente aumento na criação do curso, Castro e Vilarim (2013) chamam a atenção para alguns fatores como: a identidade do curso, sobre o que ensina e para quem, adequação pedagógica, além da constante preocupação com o mercado de trabalho, uma inquietação quanto à dimensão de atuação dos licenciados,

(...) os cursos de LC possuem as fortalezas e fraquezas inerentes a uma das modalidades mais recentes de cursos de graduação na área. Se, por um lado, eles articulam a promoção de saberes para além da área de Computação pura, dialogando com as fundamentações teóricas e as práticas da área pedagógica, por outro carecem de compreensão do imenso potencial de atuação dos seus egressos. ( p. 03).

A área da computação antes focada no mercado, hoje tem também um foco voltado para a educação, preparam pessoas para atuar como professores, o que este autor descreve como "[...] 'formar os formadores', os futuros professores de Computação". (p. 02). "O licenciado em Computação é principalmente responsável por apresentar a Computação como ciência à escola, e por consequência à sociedade". (REFERENCIAIS DE FORMAÇÃO PARA CURSOS DE GRADUAÇÃO EM COMPUTAÇÃO 2017, p. 86). Essa preocupação com a sociedade existe e é enfatizada nas diretrizes curriculares, nos benefícios do curso para a sociedade.

\section{As Licenciaturas em Computação: O Curso}

O avanço tecnológico que tanto transforma a sociedade, desafia, provoca às escolas, e com isso houve a necessidade de um ensino que contemple estas demandas; unido os saberes da pedagogia com a técnica e saberes da computação como ciência. Assim, o licenciado em computação, é o docente capaz de contribuir para o processo de ensino e de aprendizado, assumindo como ponto de partida a computação. "Genericamente, todo sistema computacional com funcionalidade pedagógica ou que necessita de assistência para seu uso, requer a participação dos Licenciados em Computação". (Brasil, 2012, p. 04). Pois, possui em sua composição curricular uma boa base em computação com objetivo de conhecer aplicações de ciências da computação, assim como em pedagogia para conhecimento das ciências educacionais. 
Na busca por uma melhor reflexão sobre o curso da Licenciatura em Computação - LC surgiram os Referenciais de Formação para Licenciatura em Computação (RF-LC) com intuito de explanar "(...) eixos de formação, competências e conteúdos que ajudarão a desenvolver o perfil desejado". Onde, também por meio deste “(...) busca-se oferecer um referencial de orientação para a concepção de currículos de Curso de Licenciatura em Computação adequados às atuais DCN's e para a adequação de cursos existentes às novas exigências dessas diretrizes". [REFERENCIAIS DE FORMAÇÃ̂O PARA CURSOS DE GRADUAÇÃO EM COMPUTAÇÃO 2017, p. 81].

A organização do Curso de Licenciatura em Computação é definida através do seu Projeto Pedagógico, que incorpora de forma detalhada e com base nas diretrizes curriculares vários elementos, dentre eles; o perfil do egresso, conteúdos curriculares, habilidades, competências, organização curricular, estágio supervisionado, trabalho de conclusão de curso, atividades complementares, acompanhamento e avaliação. Além de elementos estruturais necessários para operacionalização do curso.

Como perfil do profissional é esperado que o Licenciado em Computação atenda ao que estabelece a Resolução CNE/CP $n^{\circ} 2 / 2015$ no perfil geral para os egressos dos cursos de Formação de Professores para a Educação Básica e conforme Resolução CNE/CES Nº 5/2016, que o licenciado esteja habilitado a operar no espaço educacional nas áreas da computação voltada à educação, promovendo a interdisciplinaridade, atuando no desenvolvimento de software e hardware voltados à pedagogias com tendência a tecnologia, aplicação do pensamento computacional com aproveitamento para a educação e a vida cotidiana, projetos de interação humano-computador, além de outros ambientes como: empresas do ramo da computação, informática, tecnologia e áreas correlatas. Espera-se que esse profissional domine conhecimentos das áreas da ciência da computação, matemática e educação, além do senso de investigação e reflexão.

A Licenciatura em Computação oportuniza ao profissional atuação no Ensino Médio, Fundamental e também em Ensino Técnico e Profissionalizante, além de outros campos voltados para a área da computação. O que inclui também a Educação a Distância $(\mathrm{EaD})$ e as plataformas e-learning, bem como formar educadores para o ensino de computação e recursos humanos capazes de planejar sistemas de software educacional, categorias que "(...) exige a constituição de equipes interdisciplinares em que os integrantes tenham conhecimentos de Computação e Educação, como espera-se dos egressos dos cursos de Licenciatura em Computação". [REFERENCIAIS DE FORMAÇÃO PARA CURSOS DE GRADUAÇÃO EM COMPUTAÇÃO, 2017, p. 84]. É uma profissão que conversa com outras áreas, outras disciplinas. Podendo assim, atuar no espaço escolar como facilitador na inserção das tecnologias nesse ambiente.

\footnotetext{
Nesse sentido, o curso de Licenciatura em Computação deve promover o fortalecimento da construção de identidade com o magistério, desfazendo mitos e incentivando experiências que estabeleçam conexões com os diversos saberes inerentes à prática do magistério para além da regência de classes (Matos, 2013, p. 27).
}

Espera-se que os egressos tenham perfil com competências e as atitudes estabelecidas pelas Instituições com base nas mesmas. $\mathrm{O}$ curso passa por avaliação com objetivo de identificar pontos fracos com vista a manter a qualidade, buscando soluções para tratá-los, assim como identificar também sua potencialidade. Conforme descrito nas diretrizes curriculares (1998, p. 05), para manter os objetivos do curso idêntico estabelecidos nos projetos pedagógicos e realizar ajustes quando necessário para um melhor aprimoramento, é recomendado um acompanhamento contínuo deste e uma avaliação constante. Este acompanhamento avalia o desempenho dos estudantes em relação aos conteúdos programáticos, suas habilidades e competências. Algo que 
impactará em seu percurso formativo, por isso, "O projeto pedagógico deve prever o emprego de metodologias de ensino e aprendizagem que promovam a explicitação das relações entre os conteúdos abordados e as competências previstas para o egresso do curso". (DiretrizesCurriculares 2003, p. 06).

A metodologia é um processo que promove interação entre professor e aluno, assim como, uma integração das disciplinas pedagógicas com as específicas da computação trazendo o discente a uma reflexão sobre a prática da docência e aquisição da sua identidade como licenciado em computação. Além de fortalecer também a construção do conhecimento, da autonomia, da criatividade, do senso crítico e reflexivo tornando um aluno mais ativo "(...) diante dos métodos e processos de ensino que lhe são apresentados e vivenciados". (CR-LC, 2002, p. 10). Promovendo assim o desenvolvimento das habilidades conforme previsto no perfil do egresso. Seguindo os Referenciais de Formação para Cursos de Graduação em Computação, a metodologia a ser utilizada deve está fundamentada na:

a) utilização de tecnologias contemporâneas no ensino;

b) articulação entre teoria e prática durante todo o processo de formação;

c) interação Licenciatura/Educação Básica desde o início do curso, propiciando o desenvolvimento de práticas pedagógicas críticas e reflexivas;

d) indissociabilidade entre ensino, pesquisa e extensão;

e) relação dos conteúdos com os temas transversais;

f) contextualização dos conteúdos programáticos com a realidade dos estudantes;

g) pesquisa inerente à prática docente, como estratégia de formação de professores ativos e autores. (REFERENCIAIS DE FORMAÇÃO PARA CURSOS DE GRADUAÇÃO EM COMPUTAÇÃO, 2017, p. 102).

Assim, o currículo deve estar alinhado ao contexto de uma sociedade contemporânea. Um curso voltado para a reflexão do ser professor. O currículo na sua montagem beneficia a parte técnica e a parte pedagógica de forma igual, por isso, à correlação das disciplinas pedagógicas e técnicas é de suma importância, uma ligação entre teoria e prática, integrando recursos tecnológicos a processos pedagógicos, enriquecendo o espaço escolar. Conforme descrito no perfil do egresso:

Uma formação de base sólida no que se refere à associação entre os conceitos/saberes computacionais e conceitos/saberes pedagógicos, sendo capaz de empregar os avanços e inovações tecnológicas na educação, construindo, administrando e transformando o processo de ensino-aprendizagem. (PPC IFBA - Campus Porto Seguro, 2014, p. 19).

Fato que pode ser realizado através do estágio supervisionado e prática de ensino. Sendo o estágio supervisionado componente obrigatório nos currículos das licenciaturas conforme definido na Lei 6.494/77. Embasa uma relação entre teoria e prática, onde os estudantes colocam os conhecimentos obtidos em sala de aula na prática em ambientes reais. "Assim o estágio curricular supervisionado supõe uma relação pedagógica entre alguém que já é um profissional reconhecido em um ambiente institucional de trabalho e um aluno estagiário." (Parecer CNE/CP 28/2001). O que se dará por meio de parceria entre as instituições e as escolas públicas e/ou privadas que exerçam atividades relacionadas ao curso. Vinculando assim uma afirmação de saberes.

De acordo com o Parecer CNE/CP 28/2001, o estágio curricular supervisionado da licenciatura não poderá ter uma duração inferior a 400 horas. Tendo seu início a partir do quinto 
semestre, avançando à medida que o aluno progride no curso. O Referenciais de Formação para Cursos de graduação em Computação (2017, p. 100) sugere duas áreas como possibilidades de estágio para esses licenciandos: a docência presencial e $\mathrm{EaD}$ e o projeto, desenvolvimento, aplicação e avaliação de tecnologia educacionais, pois, o intuito é que o aluno vivencie essas duas áreas. Haja vista, que o foco é a docência e que desta forma a regência de classe lhe traga uma boa experiência. Considerando que as atividades de estágio voltadas ao desenvolvimento de tecnologias educacionais dependem de aprovação do colegiado ou similar que municiou que tal feito esteja condizente com a vivência do estágio da Licenciatura em Computação. Como área de atuação de estágio é indicada:

- a docência na Educação Básica Regular;

- a docência na Educação Profissional;

- setores de capacitação de empresas, órgãos públicos ou mistos na área de Computação;

- espaços de tutoria e gestão de $\mathrm{EaD}$;

- design instrucional em ambiente de educação on-line;

- desenvolvimento e avaliação de software e hardware educacionais em ambientes escolares, empresas ou organizações sem fins lucrativos. (REFERENCIAIS DE FORMAÇÃO PARA CURSOS DE GRADUAÇÃO EM COMPUTAÇÃO 2017, p. 100).

O estágio será acompanhado por uma pessoa da instituição e outra do ambiente onde o discente o desenvolverá, “(...) seja ele voltado à docência ou à prática na indústria de tecnologias na educação". (REFERENCIAIS DE FORMAÇÃO PARA CURSOS DE GRADUAÇÃO EM COMPUTAÇÃO 2017, p. 100).

Assim como o estágio supervisionado, a Prática como Componente Curricular (PCC) é uma prática que se trabalha a reflexão sobre a atividade do professor, está amparada na Resolução CNE/CP 02/2015, deve estar planificada no projeto pedagógico. Mas, conforme esta mesma Resolução, (p. 31), é "Importante aprender tais processos e, sobretudo, situar a concepção e o entendimento do papel da prática como componente curricular e do estágio supervisionado, resguardando a especificidade de cada um e sua necessária articulação, (...)", mostrando que ainda que os dois juntamente com as atividades de trabalho acadêmico coadunem para "(...) a formação da identidade do professor como educador". (Parecer CNE/CP 28/2001), este se distingue do estágio. Sendo confirmado no Parecer CNE/CES no 15/2005,

“(...) a prática como componente curricular é o conjunto de atividades formativas que proporcionam experiências de aplicação de conhecimentos ou de desenvolvimento de procedimentos próprios ao exercício da docência. Por meio destas atividades, são colocados em uso, no âmbito do ensino, os conhecimentos, as competências e as habilidades adquiridas nas diversas atividades formativas que compõem o currículo do curso". (p. 03).

Como justificativa do exercício da teoria e da prática, O Parecer CNE/CP no 9/2001 (p. 02) diz ainda que estas atividades não devem ficar fechadas, reduzida apenas ao estágio supervisionado, que é necessário abranger o restante do curso e que devem ser criadas 'situações didáticas' e fazer uso do que foi aprendido ao tempo em que se buscam outros aprendizados de outras 'naturezas', advindas de outras 'experiências' em diferentes 'tempos' e 'espaços curriculares'. Complementa ainda que:

Uma concepção de prática mais como componente curricular implica vêla como uma dimensão do conhecimento, que tanto está presente nos cursos de formação nos momentos em que se trabalha na reflexão sobre a 
atividade profissional, como durante o estágio nos momentos em que se exercita a atividade profissional. (Parecer CNE/CP 9/2001, p. 23).

A parte prática nos cursos de licenciaturas tem sua duração de 400 horas mínima, distribuído desde o início do curso conforme planejado em seus currículos. Conta com a supervisão da instituição formadora, a fim de apoio e uma avaliação qualitativa. As metodologias a serem adotadas nesta fica a cargo do colegiado, devendo estar explícitas no projeto pedagógico as quais devem refletir a realidade escolar, e podem

(...) ser desenvolvidas como núcleo ou como parte de disciplinas ou de outras atividades formativas. Isto inclui as disciplinas de caráter prático relacionadas à formação pedagógica, mas não aquelas relacionadas aos fundamentos técnico-científicos correspondentes a uma determinada área do conhecimento.

As disciplinas relacionadas com a educação que incluem atividades de caráter prático podem ser computadas na carga horária classificada como prática como componente curricular, mas o mesmo não ocorre com as disciplinas relacionadas aos conhecimentos técnico-científicos próprios da área do conhecimento para a qual se faz a formação. Por exemplo, disciplinas de caráter prático em Química, cujo objetivo seja prover a formação básica em Química, não devem ser computadas como prática como componente curricular nos cursos de licenciatura. Para este fim, poderão ser criadas novas disciplinas ou adaptadas às já existentes, na medida das necessidades de cada instituição. (Parecer CNE/CES 15/2005, p. 3).

No exercício da atividade docente, a prática é importante para o aprofundamento e ampliação do conhecimento. Essa pluralidade de atividades configura um licenciado preparado para trabalhar a (inter), (múltipla) e (trans)disciplinaridade de forma criativa, reflexiva e autônoma. Garantido uma integração de qualidade nos espaços escolares, também na utilização dos recursos tecnológicos, assim como, dos processos pedagógicos. E as atividades complementares complementam esse processo. Também conhecidas como ACC (Atividade Complementar de Curso), horas complementares ou extracurriculares. São atividades extras realizadas pelos alunos fora do período de aula. Configura como atividades não curriculares que contribuem para a ampliação de suas habilidades e competências. Conforme Art. 13 da Resolução $\mathrm{CNE} / \mathrm{CP} \mathrm{n}^{\mathrm{o}} 02$, de $1^{\circ}$ de julho de 2015 , a atividade complementar deve ter uma carga horária mínima de $200 \mathrm{~h}$, podendo estas ser compostas por atividades acadêmicas, científicas, técnicas, culturais e sociais. A mesma deve estar em consonância com a proposta do curso e ser executada no decorrer deste. É recomendado que os alunos desenvolvam ao menos "duas das três dimensões da atividade acadêmica: ensino, pesquisa e extensão". (REFERENCIAIS DE FORMAÇÃO PARA CURSOS DE GRADUAÇÃO EM COMPUTAÇÃO 2017, p. 100).

Dentro desse processo de aprendizado adquirido no decorrer do curso, o aluno será direcionado para confecção do Trabalho de Conclusão de Curso (TCC), que configura um trabalho individual, é de autoria do discente, é como uma fusão do conhecimento construído no transcorrer do curso e "(...) será desenvolvido como atividade de síntese, integração ou aplicação de conhecimentos adquiridos de caráter científico ou tecnológico". (Resolução 05/2016, p. 8). Contudo, sua obrigatoriedade fica a cargo de cada instituição, assim como a definição dos regulamentos. Apesar disso,

Para os cursos orientados para transformar processos é fortemente recomendado que seus alunos escrevam, apresentem e defendam um Trabalho de Curso, aplicando os conhecimentos adquiridos (no estado da 
arte) no desenvolvimento de aplicações científicas ou tecnológicas, preferencialmente inovadoras. (Parecer CNE/CES 136/2012, p. 16).

Considerando que,

Algumas das funções dos egressos dos cursos de bacharelados e de licenciatura da área de Computação são predominantemente orientadas para realizar atividades de processos e outras para transformar processos, com o desenvolvimento de novas tecnologias.

(Parecer CNE/CES 136/2012, p. 15).

"Nessa perspectiva, as práticas enquanto componentes curriculares e os estágios supervisionados suprem a necessidade de formação articulada à prática profissional do Licenciando em Computação". (REFERENCIAIS DE FORMAÇÃO PARA CURSOS DE GRADUAÇÃO EM COMPUTAÇÃO 2017, p. 100).

\subsection{Licenciatura em Computação: Atividades docente para o ensino da Computação}

A vivência habitual da tecnologia na sociedade demonstra o quão fundamental é a presença do profissional com formação na área da computação, e no cotidiano escolar é exigido conhecimentos de Computação e Educação. Nesse contexto, foi pensando na sociedade, na educação, na tecnologia que as DCNs [Resolução CNE/CES no 05/2016] destacam no seu Art. $4^{\circ}$, requerer um profissional dotado de conhecimento conforme diz o inciso II - "da compreensão do impacto da computação e suas tecnologias na sociedade no que concerne ao atendimento e à antecipação estratégica das necessidades da sociedade".

Presente em diversas áreas da sociedade, a computação está nas empresas, nas escolas, nos domicílios, fazendo parte da nossa vida diária. Aliado aos avanços tecnológicos e a extensa possibilidade pedagógica traz a necessidade de desenvolvimento de atividades com a utilização do computador. Diante do atual cenário educacional (momento em que escolas foram paralisadas devido a Pandemia causada pelo COVID-19) com as TICs (Tecnologia da Informação e Comunicação) em evolução na educação, a Licenciatura em Computação ganha destaque na sociedade da informação. Podendo ser o professor que forma professores, o desenvolvedor de novas tecnologias, o mediador em plataformas EAD, dentre outras competências ligada a sua formação. Embora, algumas escolas públicas não tenham adotado o sistema de aulas remotas por diversos motivos, alguns outros setores como empresas e escolas particulares aderiram. Em muitos desses casos, a capacitação tecnológica é necessária para uso adequado de equipamentos. Como explica Prietch e Pazeto, (2009),

Constata-se uma carência de profissionais de educação em computação, o que priva as escolas, do ensino de disciplinas desta área em cursos profissionalizantes; da introdução de fundamentos dessa ciência nos currículos regulares da educação fundamental e média; da interlocução em projetos interdisciplinares e transversais; da informatização escolar; da busca, análise e projeto de softwares educacionais e objetos de aprendizagem de qualidade, dentre muitos outros.

Seguindo o que fora descrito por estas, compreende-se que o Licenciado em Computação não é apenas o interlocutor entre a educação e as TICs. É um profissional qualificado também para o ensino da Ciências da Computação.

Considerando também que professores e alunos são sujeitos sociais que possuem computadores e celulares ligados à internet, faz-se necessário que a educação e o ambiente escolar atualizem-se frente ao mundo tecnologicamente digital. AYALA (2017 apud Ayala \& Rocha, 
2018). Dessa forma o Licenciando em Computação amplia seu campo de atuação e adquire um potencial de participação numa sociedade tecnologicamente moderna.

À medida que a tecnologia evolui, a indústria, a educação, a ciência e toda uma diversidade de setores também evoluem. Portanto, esse processo de evolução e inovação também é concebido ao Licenciado em Computação no desenvolvimento da sua profissão, justificando assim porquê, para quê ou quem ensinará as gerações atuais e futuras se a Computação está e tende a ficar cada vez mais presente em nossas vidas, conforme questionado por Castro e Vilarim (2013).

Todavia, o que de fato diferencia um docente que utiliza a tecnologia em sua disciplina e o docente que é Licenciado em Computação na escola, é que A Licenciatura em Computação é a formação de profissionais para atuar no ensino de computação e informática na educação básica, fundamental, média e superior, quanto que o professor que utiliza tecnologia ele transforma e melhora sua metodologia de ensino. Os licenciados em computação, também podem colaborar com a capacitação desses professores no uso das TICs para a educação. Não basta apenas aprender a utilizar o computador como meio pedagógico, é necessário desenvolver práticas de conhecimentos, aguçar o pensamento crítico e reflexivo nos alunos, e que estes possam ser capazes de aplicá-lo em situações apropriadas.

Isso evidencia que o curso tem por objetivo preparar profissionais para a sociedade e seus desafios contemporâneos. (REFERENCIAIS DE FORMAÇÃO PARA CURSOS DE GRADUAÇÃO EM COMPUTAÇÃO 2017, p. 84).

\section{Análise, contribuições e estudos correlatos}

Ao longo dos anos, o homem vem arquitetando novas tecnologias para facilitar o dia a dia das pessoas, direcionando-as a fazer uso cada vez mais dessas invenções. Estamos ligados em todos os sentidos a tecnologias a qual vem tendo uma abrangência desde a vida profissional até a vida pessoal. Atualmente não se tem vivido apenas pela informação, ou seja, pela recepção dessa informação, mas, sim pelos conhecimentos aplicados a estas. Conforme (Castells, 1999, como citado em Junior et al., 2005),

(...) uma era que se caracteriza não pela centralidade de conhecimento e informação, mas pela aplicação destes conhecimentos e informações na geração de novos conhecimentos e de dispositivos de processamento/comunicação da informação, em um ciclo de realimentação cumulativo entre inovação e seu uso. (p. 02).

Assim, muitas atividades operacionais vêm sendo substituídas pela máquina, devido à rapidez e operacionalidade. Neste contexto, o mercado tem exigido pessoas com conhecimentos técnicos, qualificadas para estruturar logicamente instruções para que o computador as execute. Pessoas que entendam como programar, que seja não apenas consumidoras de tecnologia. Para Valente (1993, p.12), "o computador não é mais o instrumento que ensina o aprendiz, mas a ferramenta com a qual o aluno desenvolve algo". Corroborado por Papert (1985, p. 09) quando diz que "o computador deixa de ser o meio de transferir informação e passa a ser a ferramenta com a qual a criança pode formalizar os seus conhecimentos intuitivos". Este, já em 1985, percebeu que o computador seria portador de várias ideias. No que denominou de Construcionismo, Papert (1985) já chamava a atenção para o aprendizado do aluno por meio do computador. Que este, poderia auxiliar o homem na aquisição do conhecimento e na relação deste com a ciência e com os próprios seres. De como promoveria mudanças culturais, de como afetaria a maneira de pensar e aprender das pessoas. Mostrou também o desenvolvimento do pensamento e as mudanças nos meios de acesso ao conhecimento. Ele relata que muitos autores ao investigar sobre um "futuro repleto de computadores", sobre o que as pessoas seriam capazes de fazer com eles, estas ressaltam “(...) seu uso para jogos, diversão, imposto de renda, correspondência eletrônica, compras e operações bancárias. Poucos falavam sobre o computador como uma máquina de ensinar". (Papert 1985, p.15). Hoje, é notório o quanto a tecnologia trouxe 
estas e outras transformações para a sociedade de um modo geral. E a escola está também associada a essa transformação, embora tente escapar. Com tanta informação disponível isto impacta em seu modelo de ensino e de aprendizagem.

Com a perspectiva de mudança na educação, a informática foi inserida na educação pública com intuito de oferecer inclusão digital para a sociedade e assim, aproximar a cultura escolar dos avanços tecnológicos. Valente e Almeida (1997) fazem uma análise dos programas de implementação da Informática nas escolas dos Estados Unidos da América e França e a influência que tiveram estes sobre o programa brasileiro, uma das observações, é que no programa brasileiro o computador tem o papel de provocar mudanças pedagógicas profundas ao invés de "automatizar o ensino" ou promover a alfabetização em informática como nos Estados Unidos, assim como na França que trabalha o desenvolvimento da capacidade lógica e a preparação do aluno para o trabalho em empresa. Contudo, Castro \& Vilarim (2013) questiona quem ensinará as gerações atuais e futuras? Nesse processo de informatização das escolas, ganha destaque o Licenciado em Computação - professor formado pelo curso de Licenciatura em computação. Um curso que segundo Matos e Silva (2012) aponta novas perspectivas de formação, bem como novos desafios e a necessidade de um curso com identidade própria. Na formação dessa identidade é incorporado saberes diferenciados dos bacharelados da área de computação (saberes científico e tecnológico), conta com saberes científico, tecnológico e pedagógico. Um profissional que está habilitado a atuar no Ensino Fundamental, Médio e também em Ensino Técnico e profissionalizante, Educação a Distância (EaD), além de outros campos voltados para a área da computação.

Prietch e Pazeto (2009) ressaltam, que por se tratar de um curso de licenciatura na área computacional as considerações sobre as atualizações contínuas são necessárias e desejadas, assim como, precisam "manter seus Projetos Políticos Pedagógicos atualizados". "No entanto, para um curso de licenciatura nesta área a dificuldade de encontrar profissionais que atendam às expectativas da área acadêmica e tecnológica, torna o processo de inovação ainda mais complexo." (Prietch e Pazeto, 2009). Justificando assim um profissional da área, com identidade própria e saberes científicos, tecnológicos e didático-pedagógicos. A Licenciatura em Computação é um curso que ainda precisa ser consolidado perante a comunidade da escola pública. Pois, para Matos e Silva (2012) os conhecimentos da computação já fazem parte da "formação intelectual e cidadã, uma vez que são fundamentais para a vida social e contemporânea".

\section{Considerações finais}

Este trabalho teve como objetivo remontar a trajetória de implementação dos Cursos de Licenciatura em Computação, no Brasil. Pois conforme Prietch, Pazeto e Dias (2011), “(...) fatos históricos não devem ser esquecidos, pois trazem aprendizado para as atividades presentes, bem como entendimento do futuro". A abordagem qualitativa, por meio de uma pesquisa histórica, na qual foram levantados fatos, decretos, ações governamentais e artigos de vários autores como: (Castro e Vilarim, 2013), (Matos, 2013), (Matos e Silva, 2012), (Nunes, 2015), (Prietch e Pazeto, 2009, 2010), (Prietch, Pazeto, \& Dias, 2011), (Valente, 1997), etc, que permitiram a remontar esta trajetória e fundamentar o texto. A produção deste, contou com a compreensão e análise das normativas produzidas para a área, bem como os movimentos via Ministério da Educação e instituições que norteiam e orientam a história recente destas licenciaturas no contexto brasileiro. Com base em tal levantamento é possível inferir primeiramente sobre a notoriedade e importância destes cursos para o nosso tempo; segundo sobre a necessidade da formação deste futuro docente ser aprimorada na prática por meio de implementações de metodologias inovadoras, vinculadas tais como a prática de resolver problemas no cotidiano das escolas; e terceiro a necessidade de ampliação do campo de emprego para estes docentes no contexto das Redes de ensino. 
Lembramos que com o surgimento do modelo Pensamento Computacional, inicialmente anunciado pela pesquisadora Jeannette $\mathrm{M}$. Wing ${ }^{3}$, o curso da Licenciatura em computação vem ganhando evidência, pois, o modelo de ensino vem recebendo alguns destaques por parte das escolas particulares, assim como a robótica, os jogos digitais, a interdisciplinaridade e nesse momento as aulas remotas, vista como um desafio e uma oportunidade para a área, pois, mesmo tendo em vista que é uma necessidade do ensino, ainda necessita de (re) estruturação da prática pedagógica e das escolas públicas sobre a necessidade em perceber as mudanças da sociedade e fortalecer as metodologias para lidar com essas transformações.

O ensino, enquanto ação humana, tem passado por uma grande mudança consequente das variáveis sociais, econômicas e políticas que influenciam, direta ou indiretamente a educação. Novos conhecimentos, práticas e técnicas, bem como novos espaços para ensinar e aprender, para construir e compartilhar conhecimento tem surgido. (Matos, 2013, p. 27).

Nesse contexto, é fundamental para os espaços escolares a presença do licenciado em computação perpetrando essa integração dos recursos tecnológicos com as técnicas pedagógicas para o fomento da interdisciplinaridade, tendo em vista que as tecnologias digitais ampliam o campo da interação, da comunicação, além de integrar as áreas do conhecimento, e que tudo isto está presente numa realidade atual. Contudo, apesar de ser um curso iniciado por volta dos anos 90 e está em constante crescimento, ainda enfrenta problemas de identidade, todavia, Matos (2013, p. 27), descreve que “(...) a didática e o currículo devem promover o fortalecimento da construção de identidade com o magistério, desfazendo mitos e incentivando experiências que estabeleçam conexões com os diversos saberes inerentes à prática do magistério". Haja vista, que "O ser professor não se realiza espontaneamente. Na formação do ser professor, é imprescindível um saber profissional, crítico e competente e que se vale de conhecimentos e de experiências". (Parecer CNE/CP 28/2001). Isso é o que permite o perfil do egresso do licenciado em computação, um docente com habilidades, conhecimentos e atitudes para desenvolver práticas enriquecedoras e/ou implementadoras de novas ações dentro e/ou fora do ambiente acadêmico. Desta forma, poderá "enriquecer e expandir o perfil do egresso com atividades que privilegiam aspectos diversos da sua formação". (Parecer CNE/CES 136/2012, p. 16).

Levando em conta que em sua caracterização o currículo da licenciatura em computação o distingue do bacharelado e que sua identidade lhe garante um processo de formação contínuo. A Licenciatura em Computação educa para a autonomia.

Com base no estudo aqui realizado, vimos a necessidade de estudos futuros, onde, pretende-se, assim, analisar-se os currículos do curso Licenciatura em Computação e de que forma é realizada essa relação tecnologia - pedagogia na prática e na teoria.

\section{Referências}

Appio, J; Frizon, N. N.; Canopf, L.; Marcon, D.; Madruga B. (2017). Pesquisa Histórica como uma possibilidade à pesquisa em Estudos Organizacionais. Congresso Ibero Americano de Investigação Qualitativa. Investigação Qualitativa em Ciências Sociais. Volume 3, Atas CIAIQ 2017. Disponível em: [GS Search]

\footnotetext{
3 Jeannette M. Wing: autora americana do trabalho intitulado "Computational Thinking", professora de Ciência da Computação e chefe do Departamento de Ciência da Computação na Universidade de Carnegie Mellon, Pittsburgh, PA.
} 
AYALA, L. A.; ROCHA, E. M. (2018). O curso de licenciatura em computação e o campo de atuação profissional: o que dizem seus egressos. CIET:EnPED 2018. ISSN 2316-8722. Disponível

em: http://cietenped.ufscar.br/submissao/index.php/2018/article/download/306/375/.

Bachelard, G. (1977). O espectro filosófico. In: Epistemologia. Rio de Janeiro: Zahar. Disponível em: [GS Search]

Base Nacional Comum Curricular (BNCC) (2017). Educação é a Base. Brasília, MEC/CONSED/UNDIME, 2017. http://basenacionalcomum.mec.gov.br/a-base. [GS Search]

Brasil. (1996). Casa Civil. LEI No 9.394, DE 20 DE DEZEMBRO DE 1996. Estabelece as diretrizes e bases da educação nacional. Disponível em: [GS Search]

Brasil. (1999) Ministério da Educação. Secretaria de Educação Superior. Diretrizes Curriculares $d a$ área de Computação $e$ Informática. Disponível em: http://www.inf.ufrgs.br/ecp/docs/diretriz.pdf. [GS Search]

Brasil. (2001). Ministério da Educação. Conselho Nacional de Educação. Parecer $C N E / C P n^{o}$ 9/2001. Disponível em: < http://portal.mec.gov.br/cne/arquivos/pdf/009.pdf. [GS Search]

Brasil. (2001). Ministério da Educação. Conselho Nacional de Educação. Parecer $C N E / C P n^{o}$. 28/2001. Disponível em: http://portal.mec.gov.br/cne/arquivos/pdf/028.pdf. [GS Search]

Brasil. (2005). Ministério da Educação. Conselho Nacional de Educação. Parecer $C N E / C E S n^{o}$ 15/2005. Disponível em: http://portal.mec.gov.br/cne/arquivos/pdf/pces0015 05.pdf. [GS Search]

Brasil. (2012). Ministério da educação. Conselho Nacional de Educação. Câmara de Educação Superior. Parecer CNE/CES 136/2012. Disponível em: http://portal.mec.gov.br/index.php?option=com_docman\&view=download\&alias=11205pces136-11-pdf\&category_slug=julho-2012-pdf\&Itemid=30192. [GS Search]

Brasil. (2015). Ministério de Educação. Conselho Nacional de Educação. Conselho Pleno. Resolução CNE/CP $n^{o}$ 02, de $1^{o}$ de julho de 2015. Disponível em: http://portal.mec.gov.br/docman/agosto-2017-pdf/70431-res-cne-cp-002-03072015-pdf/file. [GS Search]

Brasil. (2016). Ministério da Educação. Conselho Nacional de Educação. Câmara de Educação Superior. Resolução CNE/CES $n^{o}$ 05, de 16 de novembro de 2016. Disponível em: http://portal.mec.gov.br/index.php?option=com_docman\&view=download\&alias=52101rces005-16-pdf\&category_slug=novembro-2016-pdf\&Itemid=30192. [GS Search]

Castro, C. S. e Vilarim, G. de O. (2013). Licenciatura em Computação no cenário nacional: embates, institucionalização e o nascimento de um novo curso. Revista Espaço Acadêmico, v. 13(148), 18-25. Disponível em: [GS Search]

de Almeida, C. C., \& Mateus, N. M. A. (2015). Licenciandos em Computação: experiências formativas proporcionadas pelo PIBID e a busca pelo reconhecimento profissional. Horizontes, V. 33, n. 1. Disponível em: DOI:10.24933/horizontes.v33i1.123. [GS Search]

Falcão, T., Araújo, D., França R., Andrade E. and França, C. (2018). Currículo da Licenciatura em Computação: uma Proposta Alinhada às Novas Diretrizes e Demandas Contemporâneas. Disponível em: DOI:10.5753/cbie.wcbie.2018.1108. [GS Search]

Fontoura, Y., Alfaia, L., \& Fernandes, A. (2013). A pesquisa histórica em estudos organizacionais no Brasil: uma análise paradigmática e novas perspectivas. GESTÃO.Org - Revista Eletrônica de Gestão Organizacional, 11(1), 83-103. Disponível em: [GS Search] 
INSTITUTO FEDERAL DA BAHIA - IFBA - Campus Porto Seguro. Projeto Pedagógico do Curso de Licenciatura em Computação. Disponível em: https://portal.ifba.edu.br/proen/departamentos/departamento-de-ensinosuperior/arquivo/ppc-superior-com-resolucao/porto-seguro/reconhecidos/curso-delicenciatura-em-computacao/porto-seguro-computacao.pdf.

Júnior, J. C. R. P., Rapkiewicz, C. E. Delgado, C. E Xexeo, J. A. M. (2005). Ensino de Algoritmos e Programação: Uma Experiência no Nível Médio. XIII Workshop de Educação em computação (WEI'²005) p. 2351-2362. São Leopoldo, RS, Brasil. Disponível em: [GS $\underline{\text { Search] }}$

Lèvy, P. (1999). Cibercultura. $3^{\mathrm{a}}$ reimpressão. São Paulo - SP: Edição 34. [GS Search]

Matos, E. S. (2013). Identidade profissional docente e o papel da interdisciplinaridade no currículo de licenciatura em computação. In: Cambraia, A. C. (Org.). Dossiê Licenciatura em Computação: reflexões teóricas e políticas. Revista Espaço Acadêmico (UEM), MaringáPR, v. 13, n. 148, p. 26-34. Disponível em: [GS Search]

Matos, E., \& Silva, G. F. B. (2012). Currículo de licenciatura em Computação: uma reflexão sobre perfil de formação à luz dos referenciais curriculares da SBC. In XXXII Congresso da Sociedade Brasileira de Computação - XX Workshop de Educação em Computação. Disponível em: [GS Search]

MEC (2016) - Catálogo Nacional de Cursos Superiores de Tecnologia. Disponível em: http://portal.mec.gov.br/index.php?option=com_docman\&view=download\&alias $=44501$ cncst-2016-3edc-pdf\&category_slug=junho-2016-pdf\&Itemid=30192. [GS Search]

MEC - Secretaria de Educação Superior. Departamento de Políticas do Ensino Supérior. Coordenação das Comissões de Especialistas de Ensino. CEECI - Comissão de Especialistas de Ensino de Computação e Informática. Disponível em: http://www.inf.ufrgs.br/mec/ceeinf.comissao.html. [GS Search]

Nascimento, J. K. F. do. (2007). Histórico da informática educativa no Brasil. In: Informática aplicada à educação: Pro funcionário Curso técnico de formação para os funcionários da educação. Brasília: Universidade de Brasília, 2007, p. 11-36. Disponível em: http://portal.mec.gov.br/index.php?option=com_docman\&view=download\&alias=606informatica-aplicada-a-educacao\&Itemid=30192. [GS Search]

Nunes, D. J. (2015). Educação Superior em Computação, Estatísticas 2015. Sociedade Brasileira de Computação-SBC. Disponível em: http://www.sbc.org.br/documentos-dasbc/summary/133-estatisticas/1074-educacaosuperior-em-Computação-estatisticas-2015. [GS Search]

Papert, S. Logo: Computadores e Educação. 1985. Trad. J. A. Valente, B. Bitelman, A. V.Ripper. São Paulo: Brasiliense. [GS Search]

Prietch, S. S.; Pazeto, T. A. (2009). Análise, Sugestões e Perspectivas de um Curso de Licenciatura em Informática. In: XVII WEI/CSBC, Bento Gonçalves/RS. [GS Search]

Prietch, S. S., \& Pazeto, T. A. (2010). Mapeamento de cursos de licenciatura em Computação seguido de proposta de padronização de matriz curricular. In XVIII Workshop de Educação em Computação [WEI 2010], Anais do XXX Congresso da Sociedade Brasileira de Computação-CSBC [p. 921-930]. [GS Search] 
Prietch, S. S., Pazeto, T. A., \& Dias, L. F. (2011). A Importância de Registrar a História de um Curso de Licenciatura em Informática. [GS Search]

Raabe, A.; Nunes, D. J.; Falcão, T. (2018). Licenciatura em Computação: impulsionando a formação de professores de computação. "Currículos para a computação no Brasil. Computação Brasil (CB). Revista da Sociedade Brasileira de Computação. Porto alegre/RS. 36p, V. 38, 2018, Ed. 03. Disponível em: https://www.researchgate.net/profile/Renata Araujo3/publication/329913456 Curriculos p ara_a_Computacao_no_Brasil_As_multiplas instigantes_e necessarias_oportunidades_de formacao na area/links/5c22bc1ea6fdccfc70690555/Curriculos-para-a-Computacao-noBrasil-As-multiplas-instigantes-e-necessarias-oportunidades-de-formacao-na-area.pdf

Santos, W. O., Hinterholz, L., \& Silva, C. (2017a). Licenciatura em computação: Desafios $e$ oportunidades na perspectiva do professor. In Anais do Workshop de Informática na Escola (Vol. 23, No. 1, p. 705). Disponível em: DOI:10.5753/cbie.wie.2017.705. [GS Search]

Santos, W. O., Silva, C., \& Hinterholz, L. (2017b). Licenciatura em Computação: Desafios e oportunidades na perspectiva do estudante. In Anais do Workshop de Informática na Escola (Vol. 23, No. 1, p. 885). Disponível em: DOI: 10.5753/cbie.wie.2017.885. [GS Search]

SBC - Sociedade Brasileira de Computação. (2018). Estatísticas dos cursos de graduação em Computação. Disponível em: https://www.sbc.org.br/documentos-da-sbc/category/133estatisticas.

SBC - Sociedade Brasileira de Computação. (2018). Parecer SBC-INEP - Reclassificação de cursos, p. 03. Disponível em: https://www.sbc.org.br/documentos-da-sbc/summary/129portarias-e-pareceres/1171-parecer-sbc-inep-reclassificacao-de-cursos-2018-04-30.

SBC - Sociedade Brasileira de Computação - Diretoria de Educação (2002). Currículo de Referência para Cursos de Licenciatura em Computação. CR-LC/2002 - Versão homologada em Assembleia da SBC em julho de 2002. Disponível em: https://www.sbc.org.br/documentos-da-sbc/summary/131-curriculos-de-referencia/763curriculo-de-referencia-lic-versao-2002.

SBC - Sociedade Brasileira de Computação. (2002). Currículo de Referência para Cursos de Licenciatura em Computação. [GS Search]

Valente, J. A. (1993) Computadores e conhecimento: repensando a educação. Campinas: UNICAMP. Disponível em: [GS Search]

Valente, J. A., \& De Almeida, F. J. (1997). Visão analítica da informática na educação no Brasil: a questão da formação do professor. Revista Brasileira de Informática na Educação, v. 1, n. 1, p. 45-60. Disponível em: [GS Search]

Zorzo, A. F.; Nunes, D.; Matos, E.; Steinmacher, I.; Leite, J.; Araujo, R. M.; Correia, R.; Martins, S. (2017) "Referenciais de Formação para os Cursos de Graduação em Computação". Sociedade Brasileira de Computação (SBC). 153p, 2017. ISBN 978-85-7669-424-3 1993. Disponível em: https://www.sbc.org.br/educacao/referenciais-de-formacao-2017. [GS Search] 